\title{
DIMENSÕES DE COMPETITIVIDADE PARA A EMPRESA BRASILEIRA: INFORMAÇÃO E CONHECIMENTO, QUALIDADE, TECNOLOGIA E MEIO AMBIENTE
}

\author{
José Carlos Teixeira da SILVA ${ }^{1}$
}

\begin{abstract}
RESUMO
Este trabalho analisa dimensões estratégicas da competitividade, em uma economia globalizada, para pequenas e medias empresas do setor de manufaturados, envolvendo a gestão da informação, a gestão da qualidade, a gestão da tecnologia e a gestão ambiental. Com base em modelo conceitual simplificado, mas de característica não linear e dinâmica, foram analisados alguns aspectos básicos desdobrados daquelas dimensões, através de referências bibliográficas e de pesquisa de campo envolvendo noventa empresas. A análise dos dados indica limitações de conhecimentos e práticas na maioria das empresas, no campo das quatro dimensões analisadas, quando comparadas a uma "organização de excelência" nesses quatro campos. As limitações em gestão do conhecimento induzem às dificuldades de implantação de sistemas de informação, sistemas de qualidade, sistemas de tecnologia, e sistemas de controle ambiental. Menos de $20 \%$ das organizações apresentam alguma configuração naquelas dimensões, porém com muita limitação em gestão da informação e gestão da tecnologia de produtos/processos, sendo a gestão ambiental dependente dessa última. Desta forma existe necessidade de ações de órgãos de governo, universidades, associações de classe, visando à conscientização e colaboração na geração de conhecimentos para essa categoria de empresas, pelos menos no campo das quatro dimensões analisadas, tendo em vista a importância das mesmas como fatores de competitividade em uma economia globalizada.
\end{abstract}

Palavras-chave: informação; organização; industria; qualidade; tecnologia.

\begin{abstract}
This paper analyzes strategic dimensions of the competitiveness in small and medium manufacturing companies, involving information, quality, technology, and environmental management. Based an a simple but not linear and dynamic conceptual model, some basic aspects of the dimensions were unfolded and investigated in field research involving 90 companies. The analysis of the data indicates that the medium apprenticeship of those companies presents limitations in the four dimensions, when compared with a "company of excellence" as a reference in those four fields. The limitation in knowledge management induces to difficulties in the implantation of information, quality, technology, and environment systems. Less than $20 \%$ of the companies present some configuration in those dimensions, but with a large limitations in information management and technology management of products processes, environmental management depending on that last one. This, there is a need of movements of consciousness of the companies through efforts from the governmental organs, class associations and universities, seeking to collaborate for the generation of knowledge in those organizations, at least in the four analyzed dimensions, because they are competitiveness factors in a global economy.
\end{abstract}

Key words: information; organization; industry; quality; technology.

1. Dr. em Engenharia-Escola Politécnica-USP. Prof. Dr. Depto. Eng. de Produção - FE - UNESP - Campus de Bauru -SP. e-mail: jcteixe@feb.unesp.br 


\section{INTRODUÇÃO}

Os sistemas operacionais têm passado por diferentes fases quanto à forma organizacional da empresa, da produção e do trabalho, em função de sua relação com o mercado e meio ambiente, envolvendo, além de outros aspectos, o desenvolvimento e utilização de tecnologias de diferentes naturezas, desde aquelas relacionadas diretamente aos produtos e processos, como também mais recentemente no campo das tecnologias e gestão da informação, comunicação e gestão do conhecimento.

A introdução da administração científica através das concepções de Taylor (1911) e Fayol (1915), bem como da contabilidade analítica, constituíram a base para o crescimento e proliferação das industrias nos países centrais, não podendo ser questionada pela sua importância e significância histórica e econômica. Com embasamento na economia de escala e prescrição do trabalho, essas organizações foram se ampliando e se burocratizando, com a criação de áreas funcionais cada vez mais numerosas, e sustentadas por um mercado insaturado e pouco exigente. Nessas condições, a qualidade dos produtos era imposta pelos fabricantes, desde a chamada era da "inspeção" até aquela do "nível de qualidade aceitável”. Somente a partir dos anos 50 e 60 é que se denota direcionamento para a garantia da qualidade e economia da qualidade, quando teve início o movimento da qualidade na industria japonesa, cujo principal enfoque foi a forma organizacional da empresa e da produção, aproveitando conceitos da área da qualidade introduzidos por Edward Deming, como relata Gitlow (1987), além de aspectos da economia da qualidade e gestão introduzidos por Juran (1951), com os primeiros princípios da qualidade total formalizados por Feigenbaum (1956). Acrescenta-se que as indústrias japonesas desenvolveram vários sistemas de gestão, mecanismos e ferramentas importantes para sistemas de qualidade, sem as quais não teriam se destacado internacionalmente nesse campo em produtos e serviços, fazendo com que as grandes empresas dos países centrais introduzissem formas organizacionais alternativas competitivas.
Portanto, o movimento da qualidade em direção à gestão da qualidade total significou rompimento em grande parte com a prática taylorista, e foi responsável pelo surgimento de nova forma organizacional para as empresas, iniciando no Japão, "orientada para as pessoas e os processos" quanto à organização interna e "orientada para as operações" quanto ao seu relacionamento com o mercado, de acordo com a classificação de Merli (1994). Desta forma, transladou-se de uma economia de escala para uma economia de escopo e de habilidade. Posteriormente essa forma organizacional se expandiu para outros países, com a caracterização de empresas "market-in" (empreendimento de classe mundial), adotando um cruzamento da abordagem orientada para o mercado dos ocidentais, com a cultura orientada para as operações, dos japoneses. O processo dessa transição, como em qualquer fase de rompimento, motivou pesquisas e trouxe criatividade e inovação dentro da abordagem da teoria organizacional das empresas. A própria gestão da qualidade total adotada pela empresas americanas já incorpora algumas diferenças da proposição japonesa, de acordo com Galgano (1992), como também alguns conceitos estabelecidos por Senge (1990), e posteriormente aspectos estratégicos de implantação delineados por Shiba (1993) em sua obra "New American TQM". Essa fase de transição, que teve início nos anos 80, e continua presentemente, tem contado com a participação ativa de vários centros de pesquisa nas áreas de administração e engenharia, nos EUA e Europa, entre eles a Harvard Business School e MIT-Massachusetts Institute of Technology, Stanford University, Cambridge University cujos trabalhos têm sido difundidos no meio acadêmico e empresarial. A introdução de alguns conceitos mais recentes vem introduzindo formas organizacionais emergentes ainda não totalmente explícitas, como a "learning organization", "organização qualificante", entre outras, cuja principal característica seria a facilidade de se adaptarem à dinâmica do meio ambiente. 
A partir da década de 90 constata-se equalização dos indicadores de qualidade entre as empresas de classe mundial, como são denominadas por Merli (1994). Teve início então uma outra fase para as organizações, em um mercado dinâmico e competitivo, que envolveu a gestão da tecnologia na empresa e mais recentemente a gestão do conhecimento. Assim, nas condições atuais, para a competitividade, as empresas devem desenvolver continuamente suas próprias tecnologias de produto/processo, gerando novos produtos/processos e serviços. Para que isso ocorra há necessidade de geração de conhecimento dentro das organizações, aspecto esse que somente poderá ser atingido com o acesso a sistemas de informação seletiva e confiável para todas as suas necessidades, e transformar essas informações em conhecimento, ou seja, utilizando-as. As empresas fora dos países centrais têm encontrado dificuldades para essa reorganização global, ou seja, desde a gestão da qualidade, a gestão da tecnologia e a gestão da informação.

A maioria das pequenas e médias empresas brasileiras, tradicionais, do setor de manufaturados, se depara com esse paradigma na atualidade, ou seja, implantar sistemas de qualidade, sistemas de gestão da tecnologia, sistemas de informação, além obviamente de obrigações recentes no que refere a aspectos de gestão ambiental e conservação de energia.

O presente trabalho é uma introdução no relacionamento das várias dimensões de competitividade das organizações na atualidade, envolvendo pequenas e médias empresas brasileiras, procurando destacar aspectos da qualidade, tecnologia, informação e meio ambiente, sempre dentro de contexto comparativo com os conceitos utilizados pelas empresas mais desenvolvidas. A relação entre as tecnologias de processo e o meio ambiente é relevante, pois os resíduos sólidos, líquidos e gasosos do processo de produção, bem como a energia consumida, são decorrentes das características da tecnologia utilizada. Se a empresa não desenvolveu essa tecnologia, terá dificuldades de manejos para redução dos resíduos e no consumo de energia, restando desta forma somente o uso de tecnologias de meio ambiente após o processo de produção, e paralisação no caso de cota de energia elétrica em programas de racionamento.

\section{COMUNICAÇÃO E GERAÇÃO DE CONHECIMENTO}

Alguns dos problemas de geração de conhecimento/aprendizagem das organizações envolvem aspectos como: dificuldades em acessar informações de maneira geral para quaisquer propósitos; dificuldades em estabelecer uma estratégia global para a empresa, começando pelos negócios, até os meios de planejamento e execução das metas; dificuldades em transferir informações e gerar conhecimentos em seu meio; reduzido empenho em estratégias de mudanças culturais e organizacionais; ausência de melhoria de processos em todos os níveis; e lentidão na adaptação aos avanços tecnológicos.

Pode-se dizer que essa aprendizagem tem sido colocada como um paradigma, pois ela é função da forma organizacional da empresa, e esta por sua vez depende da aprendizagem para sua evolução e mudanças. Essa interdependência tem sido analisada e discutida em vários trabalhos acadêmicos e empresariais, incorporando várias teorias de difícil comprovação, em função de seu aspecto qualitativo, com indicações para ser mais bem compreendida no decorrer do tempo, uma vez que esse campo de estudo não pode se basear em uma fotografia da organização. De acordo com Steesma (1996), a capacitação tecnológica está diretamente associada a aspectos organizacionais que envolvem a comunicação entre os indivíduos e a aprendizagem, ou seja, "aprendizagem organizacional é o processo de intermediação entre a interação colaborativa e a aquisição da competência técnica, sendo a aprendizagem individual necessária, mas não suficiente para a organização de aprendizagem, pois parece que o conhecimento de uma organização é diferente da soma dos conhecimentos dos indivíduos que a compõem". Dentro desse contexto, indica quatro níveis na evolução da aprendizagem, o "simples", o "adaptativo", o 
de"transição" e o "criativo", os quais determinam a capacidade ou limitação da organização em absorver informações de origem interna ou externa, gerar conhecimentos, e utilizá-los.

A organização de aprendizagem ou "learning organization", de acordo com Senge (1990), tem sido caracterizada como aquela que consegue sucesso no meio atual de intensa competição internacional, em função de sua habilidade para se adaptar rapidamente, e flexibilidade para novos negócios. Os conceitos para essa organização, indicados por Senge (1990) em sua obra "A Quinta Disciplina", envolvem as disciplinas: "objetivo comum", "modelos mentais", "domínio pessoal", "aprendizado em grupo", constituindo a quinta disciplina o "raciocínio sistêmico", a qual integra o conjunto. A disciplina "objetivo comum" incorpora uma visão da participação de cada indivíduo, em conexão com os outros indivíduos, para o objetivo principal da organização. A disciplina "modelos mentais" está ligada a conceitos e aspectos gerais, ou em imagens, que influenciam como nós entendemos o mundo e como agimos. A disciplina "domínio pessoal" está ligada à dinâmica de nova visão pessoal, concentração de energias, paciência, e visão objetiva da realidade. A disciplina "aprendizado em grupo" envolve o uso do diálogo e exercício da não presunção, caminhando para um raciocínio conjunto. A quinta disciplina "raciocínio sistêmico" incorpora uma visão ampla das inter-relações, distinta da visão linear de causaefeito, além de considerar a dinâmica do processo.
Evidentemente, a informação é transmitida através da comunicação, seja qual for o meio, diretamente pelo contato direto entre a pessoa que transmite e a que recebe, ou por outros meios, como a escrita, a telefonia, os meios de comunicação de massa como o radio e a televisão, a internet, e outros sistemas de transmissão de dados através das linhas telefônicas. Na última década do século XX houve considerável avanço da velocidade de transmissão de dados via telefonia e difusão desse tipo de comunicação para populações jamais atingidas, incluindo a própria internet, que usa o sistema de telefonia como seu principal meio de transmissão de dados. Apesar dessa evolução, a informação disponível não é seletiva, ou seja, temos dificuldades para encontrar a informação correta no momento correto. Por outro lado, a tecnologia de manejo desses sistemas de informação não é acessível para a maioria das pessoas que o utilizam, além do fato de que somente é possível encontrar na rede informações de domínio público. As informações tecnológicas das empresas não estão disponíveis, obviamente. Por outro lado, se analisarmos conceitos modernos de "tecnologia", é possível deduzir que o conceito de "transferência de tecnologia" tradicionalmente conhecido, está ultrapassado para uma economia globalizada, como a atual.

Alguns conceitos básicos diferenciam a "organização de aprendizagem" da organização tradicional, quanto à forma de gestão e comportamento individual e coletivo, de acordo com alguns aspectos abordados resumidamente e apresentados no Tabela 1 , somente para caracterizar aquela diferenciação.

Tabela 1. Diferenciação entre a organização tradicional e de aprendizagem.

\begin{tabular}{|c|c|}
\hline Organização tradicional & Organização de aprendizagem \\
\hline Decisão unilateral das gerências & Decisão interativa das gerências \\
\hline Aprendizado da organização & Aprendizado dos indivíduos \\
\hline Aprendizado adaptativo & Aprendizado e conhecimento difundido \\
\hline Os mais espertos não cometem erros & Os mais espertos aprendem com os erros \\
\hline Gerências criam compromissos para todos & Gerências promovem esforço colaborativo \\
\hline Os ditos líderes aspiram o poder & Os verdadeiros líderes aspiram servir \\
\hline O sucesso do futuro depende da previsão & O sucesso do futuro depende da habilidade \\
\hline
\end{tabular}


Evidentemente, a construção e manutenção de uma organização de aprendizagem são complexas, exigindo estratégias adequadas em cada momento da organização, como coloca Garvin (1995). Além desse aspecto, o fato de se ter atingido a "excelência" tem pouco significado, porque de acordo com Senge (1990),

“uma corporação não pode ser 'excelente' no sentido de ter alcançado a 'excelência permanente', pois ela está sempre no estado da prática da disciplina de aprendizagem do conhecimento, e pode tornar-se melhor ou pior".

Na realidade, a proposição "learning organization" parece estar relacionada a dois aspectos importantes dentro do processo de transição das empresas para a gestão da qualidade total. O primeiro diz respeito à implantação da gestão da qualidade total à moda ocidental, e o segundo pretende envolver a criatividade nas organizações, este mais complexo que o primeiro. O segundo aspecto parece ter um direcionamento para a inovação tecnológica, pouco praticada na gestão da qualidade total, uma vez que sua maior ênfase está na qualidade e produtividade. Essa caracterização para a inovação tecnológica, ou inovação em produtos, não parece estar delineada dentro da conceituação de Senge (1990), merecendo maior aprofundamento, uma vez que
(1993) definem a aprendizagem em nível mais operacional, na direção da aquisição da competência, no qual o tratamento contínuo de "eventos" e "comunicação (cognitiva, normativa e expressiva)" levam para o "modelo de competência", em direção à "organização qualificante".

A comunicação, entendida como meio de transferência de conhecimentos entre os indivíduos de uma organização, foi analisada por Nonaka; Takeuchi (1996), que consideram importante a gestão de dois tipos de conhecimentos: o conhecimento tácito (pessoal, difícil de comunicar), e o conhecimento explícito (codificado, transferível). Concluem que a gestão adequada da combinação desses conhecimentos, de acordo com o Tabela 2, conduz a uma organização inovativa, onde o conhecimento "socializado" é "externalizado", sistematizado através da "combinação", e então "internalizado". Esse modelo, designado de "hypertext organization", se baseia em processo intermediário de gestão ("middle-up-down"), no qual as gerências médias têm papel relevante, e por detrás do sistema central de negócios da estrutura organizacional há dois outros níveis conectados, o grupo de projetos ("team") e a base de conhecimentos ("knowledge background"). Essa proposição traz contribuição no contexto da comunicação dentro de uma organização, que é necessária, mas não suficiente para se conduzir à inovação tecnológica.

Tabela 2. Combinação de conhecimentos (aproximada de Nonaka; Takeuchi - 1996).

\begin{tabular}{|c|c|c|}
\hline De & Tácito & Explícito \\
Para & Socialização & Internalização \\
\hline Tácio & Externalização & Combinação \\
\hline Explícito & \\
\hline
\end{tabular}

quando se coloca um pré-requisito para uma atividade, devemos saber antes definir com clareza essa atividade e sua finalidade.

O conceito de aprendizagem coletiva deve estar vinculado às atividades da organização, e nesse contexto a comunicação entre os indivíduos constitui um fator importante e complexo. Zarifian; Veltz
Como assinalamos anteriormente, a comunicação entre indivíduos de uma organização, no contexto das atividades dessa organização, somente poderá induzir a geração de conhecimentos quando a informação estiver disponível para pelo menos um dos indivíduos. Essa transferência de conhecimento tácito para explícito, a ser absorvido pelo 
outro indivíduo, tem caráter aleatório, e depende de indivíduo para indivíduo, tanto de quem transfere como de quem recebe. Esse fato pode ser observado através de uma experiência, na qual dois indivíduos, aparentemente de mesmo nível cultural e intelectual, recebem separadamente as mesmas informações sobre um determinado assunto. Se pudermos quantificar, certamente as taxas de conhecimentos tácito e explícito seriam distintas para cada indivíduo, e obviamente também as taxas de utilização desse conhecimento. Como a organização somente progride com o conhecimento efetivamente agregado em todas as atividades, há necessidade de difundir as informações para todos os colaboradores da organização. Ainda pouco se conhece como essas informações se propagam e se dispersam na organização, e o efetivo que se transforma em conhecimento e uso efetivo. Todavia, é importante que haja disponibilidade dessa informação, sem a qual não haverá indução à geração de conhecimento. Esse conhecimento é fundamental para as empresas que almejam competitividade em uma economia globalizada, tendo em vista a necessidade contínua de aperfeiçoamentos nos campos da qualidade, tecnologia de produto/processo, e indiretamente na gestão do meio ambiente, que inclui a conservação de energia, além de aspectos mais gerais como as oportunidades de investimento e planejamento de toda a atividade operacional, quer seja na manufatura, serviços, transporte ou suprimento.

A gestão de sistemas de informação, como ferramentas e não com um fim, e a sua inserção na estratégia empresarial, são fatores-chave na criação de valor agregado e de vantagens competitivas para a empresa. Drucker (1993 a,b) considera a informação tão importante que prevê uma transposição do binômio atual capital/trabalho para informação/conhecimento, como fatores determinantes do sucesso empresarial, em cujo a informação e o conhecimento são a chave da produtividade e da competitividade. Evidentemente, dentro de uma organização existe diferença entre as características das informações necessárias para os diferentes níveis hierárquicos. Enquanto que na parte superior da pirâmide são informações de caráter mais abrangente, ou seja, macro, no centro da pirâmide informações mais gerenciais, e na base da pirâmide, no estágio operacional, informações mais específicas.Nesse contexto, alta administração da empresa deve estar conscientizada e ter firmeza de propósitos para implantação de sistemas de informação, e dispor de parâmetros para avaliar a eficiência e a eficácia desses sistemas nos resultados finais, a curto, médio e longo prazo, similarmente ao que ocorre com a implantação de sistemas de qualidade e sistemas de tecnologia.

Desta forma, a gestão da informação dentro de uma empresa também é complexa, exigindo tecnologias de informação diferenciadas, e principalmente pessoal qualificado para essa função. O hardware e o software são importantes, mas por si só não geram informação, pois constitui somente um meio de busca e comunicação de maior velocidade. Seria como se entrássemos em uma biblioteca e com alta velocidade tentássemos encontrar uma determinada informação. Muitas vezes, mesmo com menor velocidade, temos mais sucesso nessa busca, se estamos dentro de uma boa biblioteca, pois a pessoa humana tem discernimentos e perspicácias que nenhum algoritmo embutido em um software consegue detectar.

\section{CONCEITUAÇÃO E METODOLOGIA}

A abordagem do presente trabalho envolve conceitos de vários campos das empresas, que à primeira vista parecem isolados, mas na realidade estão inter-relacionados no contexto da organização como um todo, ou seja, em toda sua cadeia de valor. Assim, consideramos alguns conceitos básicos nas áreas da gestão da informação, gestão da qualidade, gestão da tecnologia, e algumas implicações decorrentes dessa configuração, relacionadas ao meio ambiente, que inclui a conservação de energia. Quanto às empresas consultadas são constituídas de pequenas (20 a 100 
colaboradores) e médias (100 a 500 colaboradores) empresas do setor de manufaturados.

A inter-relação das dimensões nesses campos pode ser estabelecida pelo modelo conceitual simplificado apresentado na Figura 1, o qual não é linear e tem características dinâmicas, como se pode constatar.

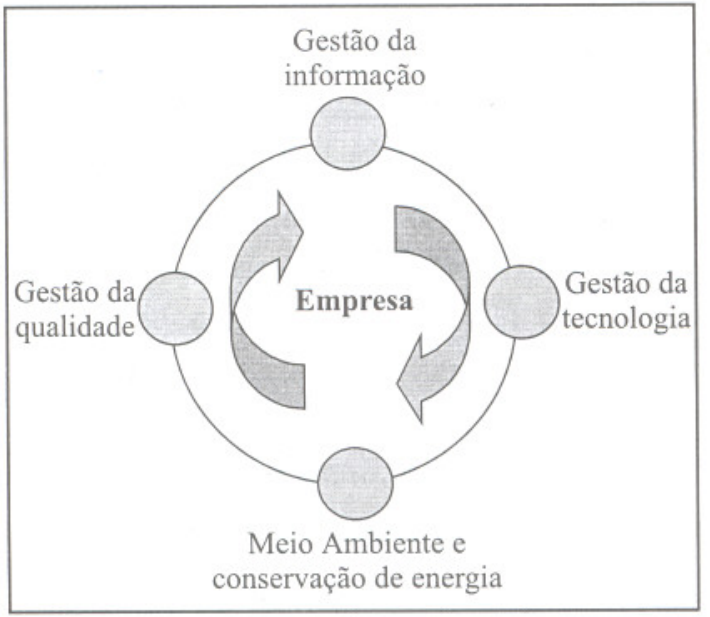

Figura 1. Aspecto do modelo conceitual da inter-relação das dimensões.

As quatro dimensões podem ser desdobradas em alguns aspectos importantes da configuração da empresa, de acordo com o Tabela 3, dentro de uma inter-relação visando implantação de sistemas de gestão da informação, sistemas de gestão da qualidade, sistema de gestão da tecnologia, sistemas de controle ambiental e conservação de energia.

A metodologia utilizada, no do campo da pesquisa organizacional, se concentra em abordagem qualitativa, caracterizando-se como projeto de pesquisa o "levantamento" ("survey") e como método de pesquisa o "questionário auto-administrado", de acordo com a concepção de Bryman (1989). Desta forma, a discussão de aspectos relacionados às "dimensões" foi conduzida com base em referências bibliográficas, e na pesquisa de campo em pequenas e médias empresas conduzida por Silva (1999a), envolvendo 90 empresas do Estado de São Paulo nos campos da qualidade e da tecnologia, com atualizações mais recentes para 60 empresas, incluindo
Tabela 3. Desdobramento das dimensões de competitividade

\begin{tabular}{|c|c|}
\hline & $\begin{array}{l}\text { Desdobramentos de aspectos das } \\
\text { dimensões de competitividade }\end{array}$ \\
\hline & Informação \\
\hline & $\begin{array}{l}\text { - Acesso à informação tecnológica } \\
\text { - Implantação de sistemas de informação } \\
\text { - Sistemas de informação via Internet } \\
\text { - Recursos humanos para gestão da informação } \\
\text { formação } \\
\text { - Comunicação entre níveis hierárquicos da empresa }\end{array}$ \\
\hline & Qualidade \\
\hline & $\begin{array}{l}\text { - Implantação de sistemas de qualidade } \\
\text { - Produtos para o mercado internacional } \\
\text { - Participação de todos para as metas da organização } \\
\text { Análise estatística de produto/processo } \\
\text { - Certificação ISO } 9000\end{array}$ \\
\hline & Tecnologia \\
\hline & $\begin{array}{l}\text { - Prospecção tecnológica } \\
\text { - Existência de comitês de tecnologia } \\
\text { - Formação de capacitação tecnológica } \\
\text { - Indicadores para uso de novas tecnologias } \\
\text { - Utilização de tecnologias patenteadas } \\
\text { - Planejamento estratégico de tecnologia de produtos }\end{array}$ \\
\hline & Meio Ambiente e conservação de energia \\
\hline & $\begin{array}{l}\text { - Meio ambiente e ISO } 14000 \\
\text { - Racionalização do uso de energia }\end{array}$ \\
\hline
\end{tabular}

aspectos da informação e meio ambiente. Quanto às referências bibliográficas, nos diferentes campos, são limitadas aquelas referentes às pequenas e médias empresas, como os trabalhos de Ghobadian; Gallear(1996) e Parkin; Parkin (1996). O questionário auto-administrado envolveu questões relacionadas às quatro dimensões, procurando delinear o comportamento das organizações, utilizando escalas de avaliação no campo da estatística não-paramétrica. Os dados em escalas nominais, dicotômicos ou de vários postos, foram analisados através de teste de aleatoriedade, teste $\chi^{2}$, e histogramas, visando o delineamento de tendências para a população. Similarmente, os dados em escalas ordinais, utilizando escalas tipo Likert (1935) apud Hayes (1992), foram analisados através de teste de normalidade, cálculo da mediana e intervalos de confiança da mediana. De acordo com Siegel (1975), a estatística mais 
adequada para a escala nominal é a freqüência, enquanto que a indicação de tendência central de uma escala ordinal é a mediana, pois "na escala ordinal geralmente os intervalos sucessivos são diferentes, o que significa que não é adequado o uso de média ou desvio padrão para tomada de decisões sobre hipóteses ou tendências". A análise dos dados relacionada às dimensões qualidade e tecnologia pode ser consultada em Silva (1999a), bem como alguns aspectos de uso de sistemas de informação na empresas. Com relação aos dados de meio ambiente e conservação de energia, e atualização para as áreas da qualidade e tecnologia, foram consultadas 60 empresas, a maioria do mesmo estudo anterior, e utilizando metodologia similar.

\section{ANÁLISE E DISCUSSÃO}

O desdobramento das quatro dimensões permitiu analisar o comportamento das empresas em alguns conceitos básicos, permitindo conhecer o estágio atual dessas organizações, com as conse- qüentes dificuldades ou gargalos a serem trabalhadas no direcionamento da competitividade em uma economia globalizada.

Na dimensão informação, como se constata na Figura 02 , apenas $3 \%$ das empresas tem sistemas de informação implantados, mas $67 \%$ delas demonstraram interesse em implantar esses sistemas. Constata-se em 7,7\% das empresas o empenho de utilização de sistemas de informação via Internet. A gestão da informação ainda não é prática comum nas empresas consultadas, apesar de reconhecerem sua importância, pois em apenas 4,2\% delas existem recursos humanos dedicados nesse campo. $\mathrm{O}$ acesso à informação tecnológica tem sido problemático, pois apenas 3\% das organizações indicaram ter acesso a esse tipo de informação através de sistemas ou outros meios. A comunicação da organização, interna e externamente, foi considerada "razoável", como mediana de uma escala ordinal que vai de "péssimo" a "excelente". Esses dados indicam que a maioria das empresas ainda desconhece os meios de

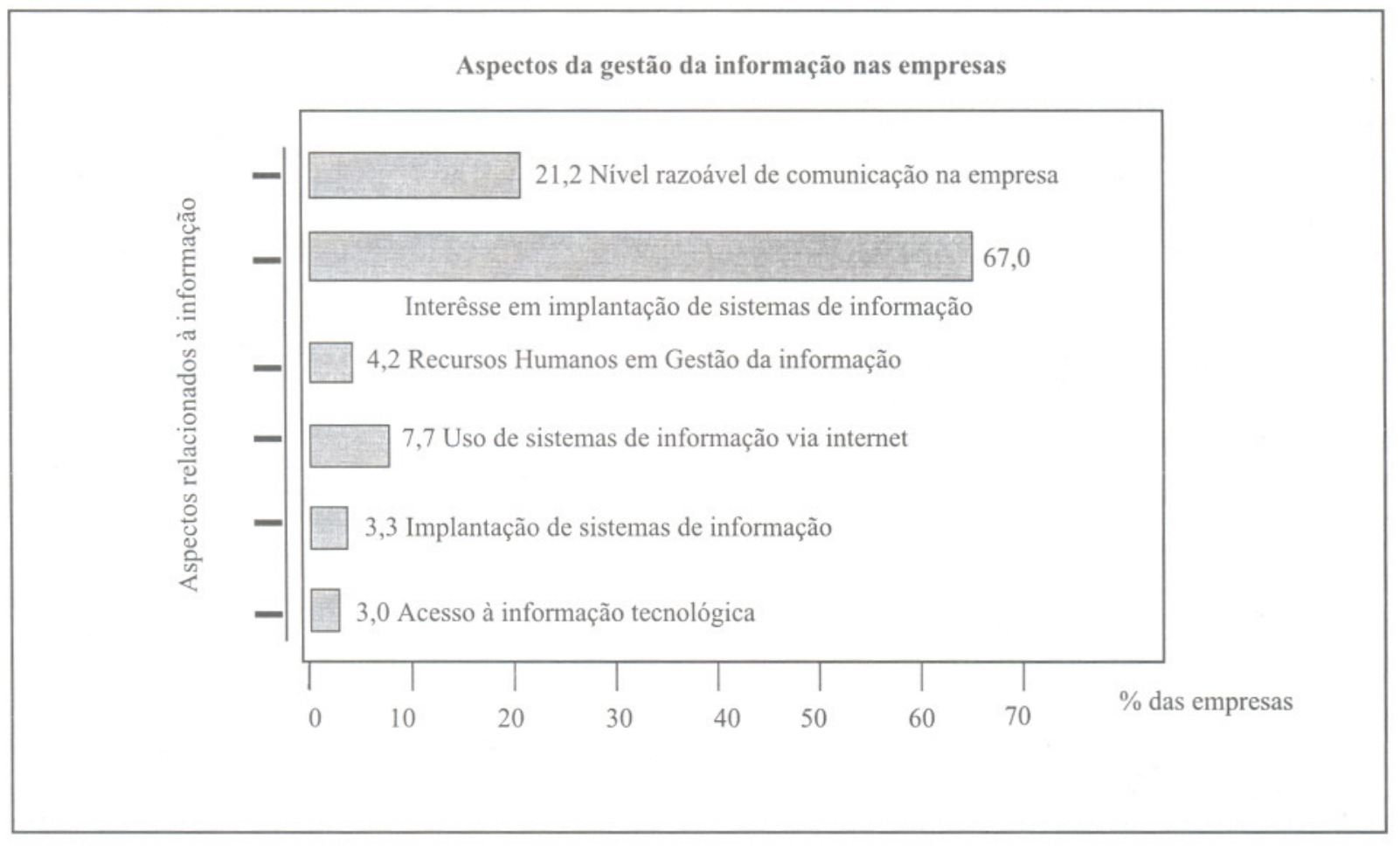

Figura 2. Aspectos da gestão da qualidade nas empresas. 


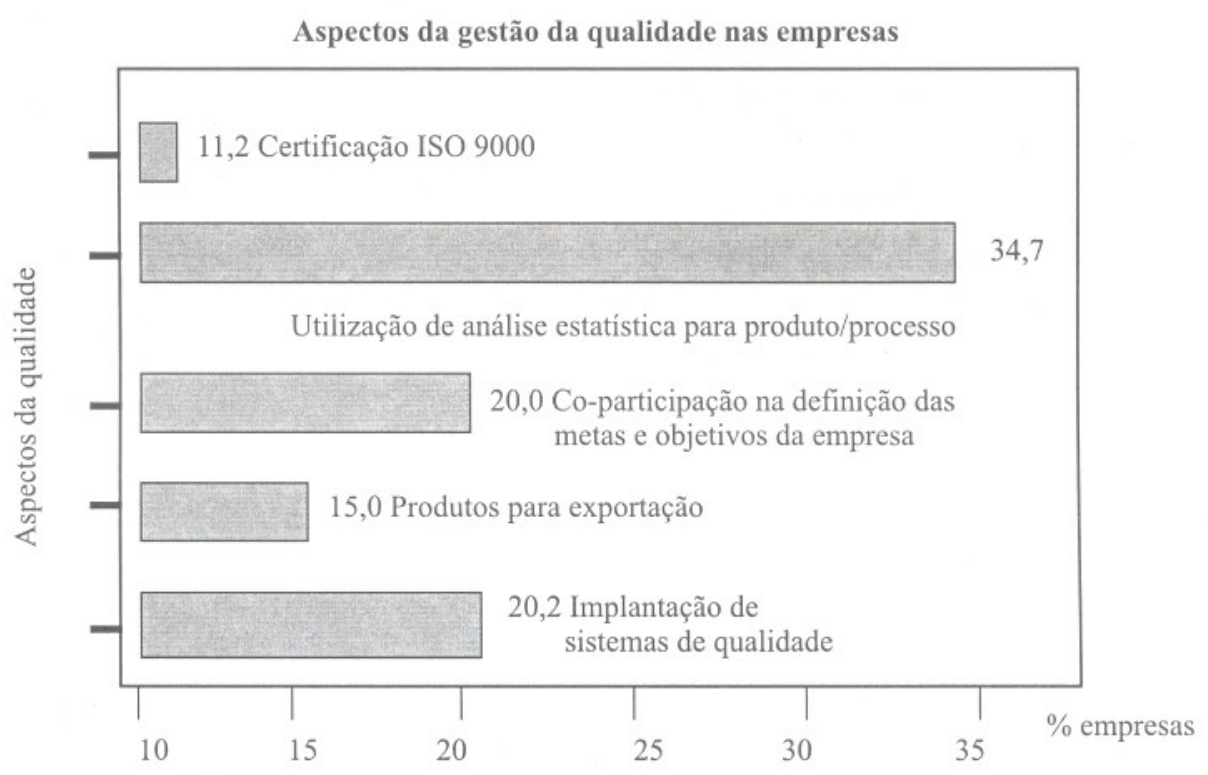

Figura 3. Aspectos da gestão da qualidade nas empresas.

acesso a sistemas de informações disponíveis no Brasil e no Exterior, apesar de sua importância para geração de conhecimentos.

Na dimensão qualidade, como pode ser observado na Figura 2, somente 20,2\% das empresas implantaram algum sistema de qualidade, e apenas $34,7 \%$ utilizam análise estatística em seus produtos e processos. Constata-se reduzida participação dos colaboradores ( $20 \%$ das empresas) na definição das metas e objetivos da organização.

Somente $15 \%$ das empresas consultadas têm atividades de exportação e 11,2\% com certificação pela ISO 9000. As informações confirmaram pesquisas anteriores, como a relatada em Silva (1999a),

Aspectos da gestão da tecnologia de produto/processo nas empresas

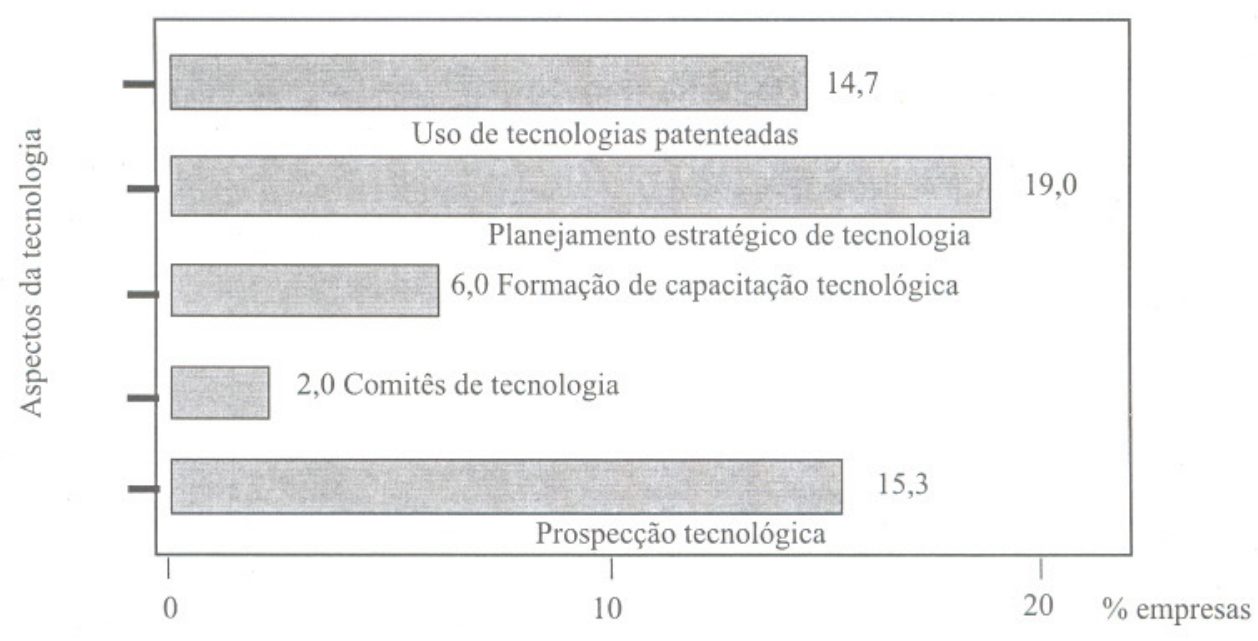

Figura 4. Aspectos da gestão da tecnologia nas empresas. 
conduzida por esse autor, onde o comportamento das empresas indica fase de transição e reorganização em direção à melhoria da qualidade e produtividade em produtos e serviços.

No campo da gestão da tecnologia, pela análise apresentada na Figura 4, apenas 20\% das empresas indicaram ter alguma estratégia em tecno- redução de custos e a produtividade foram os parâmetros mais citados, ficando a tecnologia em sétima posição. Podemos concluir, como também constatou Silva (1999b), que as empresas consultadas ainda não despertaram para a importância da dimensão tecnologia, ao contrário de empresas de outros países, como por exemplo nos USA, onde a National

Tabela 4. Parâmetros para opção de novas tecnologias de produto nas empresas.

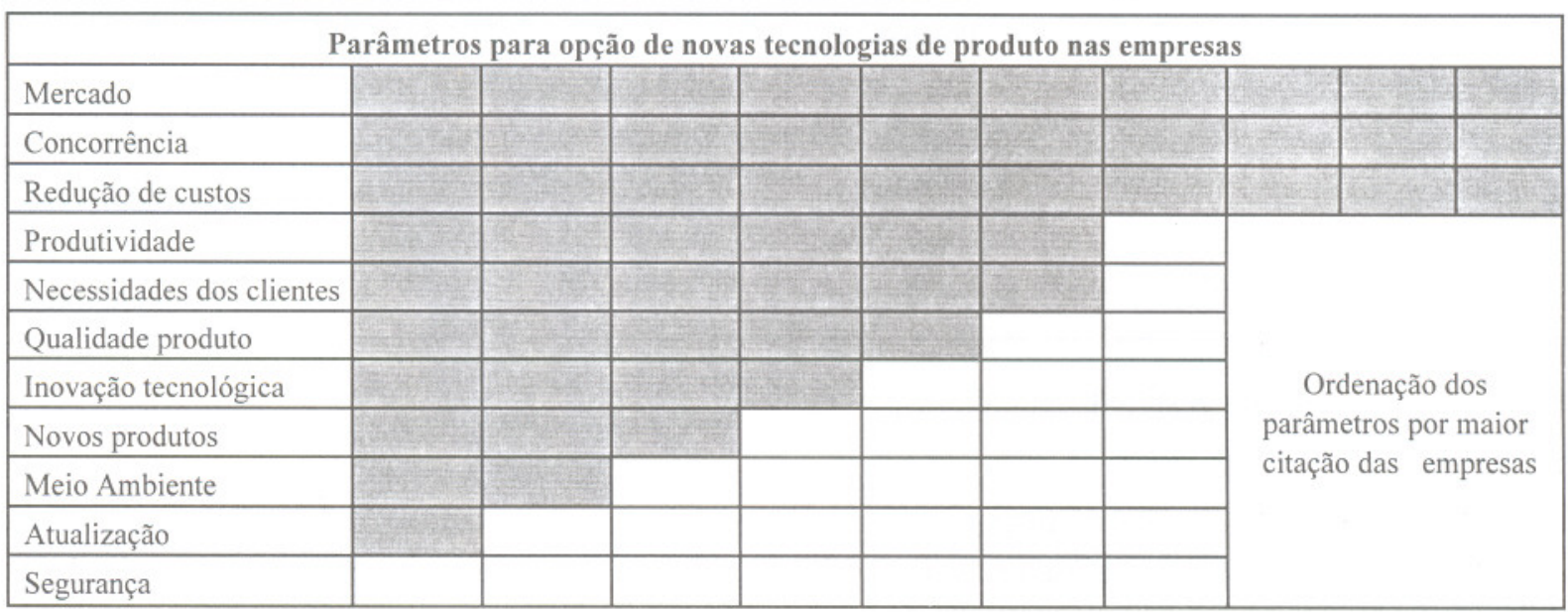

logias para produtos e processos, aspecto esse fundamental para a "capabilidade" tecnológica da empresa. A utilização de tecnologias patenteadas em somente $14,7 \%$ das empresas indicam que a maioria das tecnologias utilizadas é de domínio público. A prospecção tecnológica foi indicada como praticada por $15,3 \%$ das empresas, envolvendo principalmente a tecnologia da concorrência, ou seja, "benchmarking", ao invés da prospecção propriamente dita. Com relação a aspectos organizacionais, constata-se que a tecnologia não se estabelece como área funcional específica ou virtual, encontrando-se comitês de tecnologia em $2 \%$ das empresas, e formação de recursos humanos nessa área em apenas $6 \%$ das empresas.

Ainda no campo da tecnologia a Figura 5 relaciona os parâmetros indicados pelas empresas quando da análise para utilização de novas tecnologias de produto. $\mathrm{O}$ mercado, a concorrência, a
Science Foundation-NCF implantou uma série de programas nesse campo, envolvendo universidades e empresas na última década do século passado.

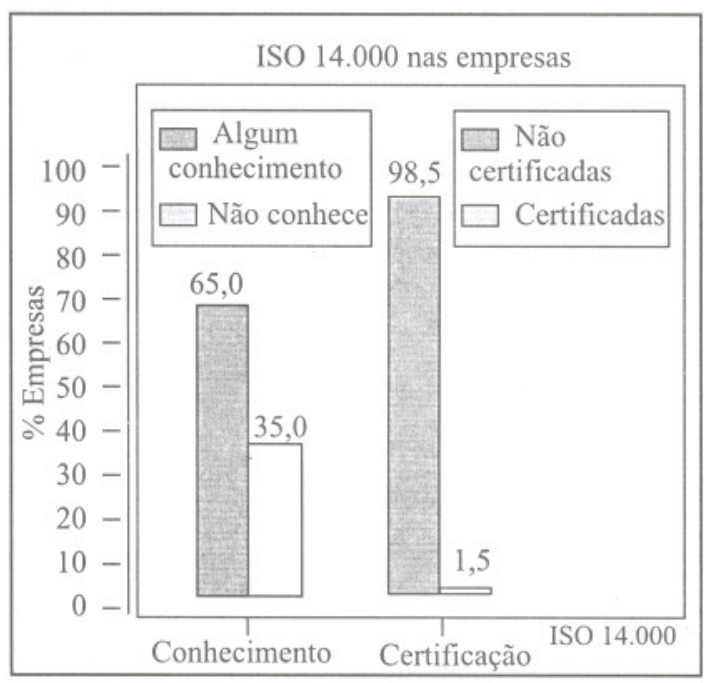

Figura 5. Conhecimento das empresas e certificação ISO 14.000 . 
Na dimensão meio ambiente analisamos dois aspectos básicos, envolvendo a ISO 14000 e a conservação de energia. Com relação à ISO 14000, os dados da Figura 6 indicam que somente $65 \%$ das empresas têm algum conhecimento dessa norma e apenas $1,5 \%$ têm certificação, comprovando a nona posição apresentada na Figura 5 quando dos parâmetros citados para utilização de novas tecnologias de produto.

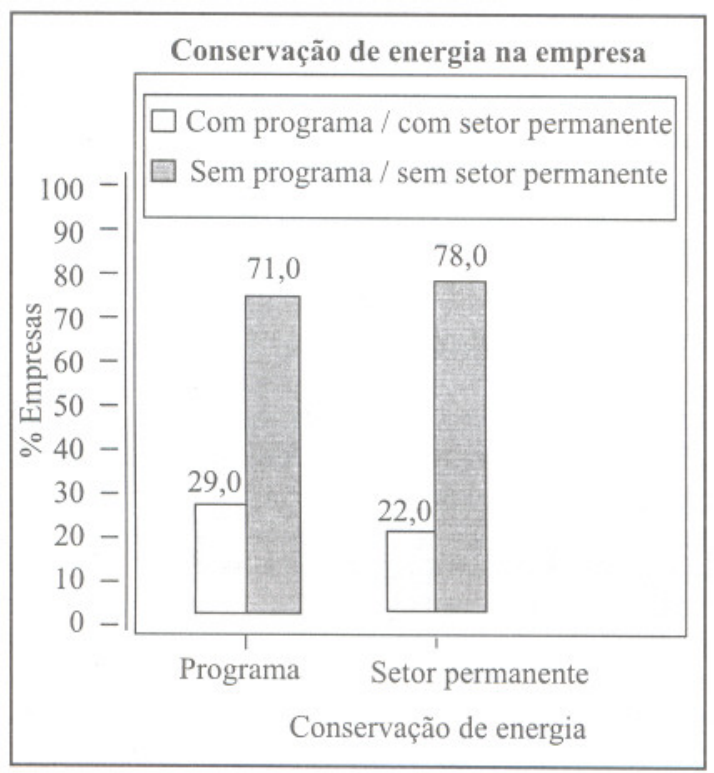

Figura 6. Programas ou setores de racionalização de energia nas empresas.

Ainda no campo de meio ambiente, a Figura 7 indica que somente $29 \%$ das empresas têm programas de conservação de energia, e apenas $22 \%$ delas instituíram setores permanentes nesse campo. Constatam-se dificuldades nas empresas para manejo de suas tecnologias de produto/processo visando redução do consumo de energia.

\section{CONCLUSÕES}

A gestão do conhecimento tem sido pesquisada no contexto das empresas, a partir da constatação da relação custo-benefício de sistemas de informação, utilizando tecnologias de informação sem a geração de conhecimento. Conhecimento e informação são duas entidades distintas. A informação, proveniente por quaisquer meios, escrita ou falada, manual ou eletrônica, transmitida por baixa ou alta velocidade, pode ser captada pelo indivíduo, decodificada e processada. $\mathrm{O}$ conhecimento gerado é residente no contexto subjetivo de ação do indivíduo, baseada naquela informação. Então, "o conhecimento reside no indivíduo e não na coleção de informação”, como já assinalava há mais de duas décadas o filósofo líder de sistemas de informação, C. West Churchman da University of Califórnia, Berkeley. Por outro lado, é evidente que sem informação não poderá haver geração de conhecimento. Essa decodificação e processamento, individual e/ou coletivo, pela sociedade ou dentro de uma empresa, é a chave da gestão do conhecimento, pois somente através dela é que a informação poderá ser útil e transformada em ação efetiva, seja para melhoria da vida na sociedade e/ou otimização de processos organizacionais e técnicos dentro de uma empresa.

Pode-se dizer que, embora por caminhos diferentes, tanto a conceituação "up-stream" de Senge (1990) para a "learning organization", como a "down-stream" de Zarifian; Vetz (1993) para a "organização qualificante", e a "middle-up-down" de Nonaka; Takeuchi (1996) para a "hypertext organization", indicam uma parte do caminho em direção à competência, criatividade, e satisfação do indivíduo no desempenho de seu papel dentro de uma organização. Apesar de toda a indicação de Garvin (1995), para um caminho em direção à organização de aprendizagem, esse campo ainda está aberto para a geração conhecimentos, como todos, dentro da conceituação da gestão do conhecimento.

O presente estudo analisou dimensões importantes da competitividade das empresas nas condições atuais de uma economia globalizada: informação, qualidade, tecnologia e meio ambiente. Constatamos limitação em disponibilidade de conhecimentos, acesso a sistemas de informação, e por conseguinte geração de conhecimentos para otimização organizacional nos campos da gestão da qualidade, gestão da tecnologia e gestão ambiental nos sistemas produtivos. Em cada um desses campos 
essa limitação vai desde o planejamento e implantação, e até a operacionalização desses sistemas. O maior gargalo ("bottleneck") está no planejamento, ou seja, o ponto de partida de toda a estruturação dos sistemas, no qual o conhecimento deveria estar concentrado, com suas respectivas ações para otimização organizacional e técnica das empresas.

Desta forma, há necessidade de que as associações ou órgãos de classe empresariais, órgãos governamentais e universidades, promovam a conscientização das empresas brasileiras da importância da geração e gestão de conhecimentos para seu desenvolvimento em campos estratégicos para a competitividade, como a informação, a qualidade, a tecnologia de produtos/processos e o meio ambiente. Um aspecto importante, válido para todos os campos, é que todo o movimento da qualidade empreendido pelas empresas japonesas, na segunda metade do século passado, foi conduzido, em sua base, sem a ajuda de computadores.

\section{REFERÊNCIAS BIBLIOGRÁFICAS}

BRYMAN, A. Research methods and organization studies. Londres: Unwin Hyman, 1989.

DRUCKER, P. Gerindo para o Futuro. Lisboa: Editora Difusão Cultural, 1993 a.

DRUCKER, P. Sociedade Pós-Capitalista. Lisboa: Editora Difusão Cultural, 1993 b.

FAYOL, H. Administração industrial e geral. Atlas S.A., 1968.

FEIGENBAUM, A. V. Total quality control. Harvard Business Review, 1956.

GALGANO, A. Calidad total. Madri: Diaz de Santos S.A., 1992.

GARVIN, D. A. Building a learning organization. Harvard Business Review, jul.-aug. de 1995.

GHOBADIAN, A.; GALLEAR, D. N. Total quality management in SMEs. Omega, vol. 24, Issue 1, pp. 83-106, Feb. de 1996
GITLOW, A. The Deming guide to quality and competitive position. New Jersey: Printice-Hall, 1987.

HAYES, B. E. Measuring customer satisfaction: development and use of questionnaires. Wisconsin - USA: ASQC Quality Press, 1992. 165 p.

JURAM, J. Quality control handbook. Nova Iorque: Macgraw-Hill, 1951.

MERLI, G. Comakership. Rio de Janeiro: Quality Mark, 1994.

NONAKA, I. ; TAKEUCHI, H. How japanese companies create the dynamics of innovation. In : CROSSAN, M. Journal of International Business Studies, Book Reviews, vol. 1, jan. de 1996.

PARKIN, M. A.; PARKIN, R. Impacto of TQM in UK SMEs. Industrial Management and Data Systems, v. 96, Issue 4, pp. 6-10, 1996

SENGE, P. M. A quinta disciplina. São Paulo: Ed. Best Seller, 1990.

SHIBA, S., A new american TQM. Cambridge: Ed. Productivity Press, 1993.

SIEGEL, S. Estatística não-paramétrica. São Paulo: Ed. McGraw-Hill, 1975.

SILVA, J. C. T. Modelo interativo empresa-universidade no desenvolvimento de produtos. São Paulo, 163p. Tese (Doutorado). Departamento de Engenharia de Produção, Escola Politécnica, Universidade de São Paulo, 1999a.

SILVA, J. C.T.; PLONSKI, G.A. Gestão da tecnologia : desafios para pequenas e médias empresas, Revista Produção, ABEPRO, Rio de Janeiro, vol. 9, n. 1, pp. 23-30, out. 1999b.

STEENSMA, H. K. Acquiring technological competencies through inter-organizational collaboration : a organizational learning perspective. Journal of Engineering and Technology Management, vol. 12, pp. 267-86, 1996.

TAYLOR, F. The principles of scientific management. New York: Harpers \& Brothers, 1991.

ZARIFIAN, P. ; VELTZ, P. Vers de nouveaux modéles d'organisation. Sociologie du Travail, Paris, vol.25, n.1, 1993. 